\title{
Trust and safety in the segregated city: contextualizing the relationship between institutional trust, crime-related insecurity and generalized trust
}

\author{
Monika Berg* and Tobias Johansson, Örebro University \\ *For correspondence monika.berg@oru.se, +4619303672
}

This is an Accepted Manuscript of an article published in Scandinavian Political Studies, 2016, 39:4, pp. 458-481,

Available online: http://onlinelibrary.wiley.com/doi/10.1111/1467-9477.12069/full

(First published 20 July 2016)

\begin{abstract}
Trust is a crucial asset for any society, and the quest to generate and uphold trust is as crucial as ever. Several contemporary societal developments are proposed as being particularly challenging for upholding and restoring the levels of trust in society, including increasing ethnic diversity, rising inequality and the related geographical segregation. It has been convincingly argued that democratic institutions may generate trust by neutralizing some of these effects. This article explores how the mechanisms of trust differ in segregated, disadvantaged neighbourhoods as opposed to the surrounding general society. The empirical material consists of individual-level data from a segregated neighbourhood (Vivalla) in a medium-sized city in Sweden (Örebro), with a random sample from the population of the city (the Vivalla area excluded) as the comparison reference point, representing the general society. In the article we introduce perceived safety as an important mediator between trust in legal and government institutions and generalized trust, through which the differing mechanisms become evident. In the disadvantaged neighbourhood, we show that trust in government institutions has the function of primarily decreasing crimerelated insecurity, which in its turn affects generalized trust. Thus, the relationship is indirect. In the city population, the effect instead goes directly from trust in government institutions to generalized trust. The results suggest that the potentials of different means to build and restore trust are dependent on local context.
\end{abstract}




\section{Introduction}

Generalized trust ${ }^{1}$ is considered particularly important in modern societies, which are individualistic, mobile, differentiated and diverse (Delhey \& Newton 2005). Meanwhile, several contemporary societal developments are proposed as being particularly challenging for upholding and restoring the levels of trust in society, including increasing ethnic diversity, rising inequality and the related geographical segregation (Putnam 2007). At the same time, it is argued that democratic institutions may generate trust by neutralizing some of these effects (Rothstein \& Stolle 2008; Hummelsheim et al. 2011). In this paper, we explore the relationship between institutional trust and generalized trust. What we are particularly interested in, however, is not the mere direct relationship, but how this relationship is mediated by perceptions of safety and how this relationship in turn differs in segregated, disadvantaged areas compared to the patterns observable in the surrounding society. We argue that there are theoretical as well as empirical reasons to believe that the relationship between institutional and generalized trust is not universal, but that it differs in different local contexts.

There is currently vivid academic debate over how diversity affects generalized trust (Putnam 2007; Gesthuizen et al. 2009; Dinesen \& Sønderskov 2012; Kokkonen et al. 2014). As a part of this debate the relationship between institutional trust and generalized trust have recently begun to be explored for specific groups in society, such as immigrants, or for differences between majority and minority populations (Kumlin \& Rothstein 2010; de Vroome et al. 2013; Dinesen 2013; Van Craen 2013). We contribute to this line of research by focusing not only on ethnicity or immigrant status as an individual characteristic (Kumlin \& Rothstein 2010) but also on the related problems of residential segregation. To study segregated, ethnically diverse and disadvantaged neighbourhoods poses particular challenges in terms of differentiating between interrelated factors such as socioeconomic disadvantage and foreign background. These factors tend to coincide at individual level and to cluster geographically, wherefore we take our empirical starting point in a particular neighbourhood context. We explore the relationships that such a particular neighbourhood context may generate in relation to a random sample from the city, in terms of how institutional trust may generate generalized trust. Such analyses contribute by detailing and specifying more thoroughly the association between institutional trust and generalized trust and allow us a better understanding of the mechanisms behind this well-storied relationship. As a consequence, we may also learn more about where, when and how institutional trust may have the potential to generate generalized trust.

Apart from the societal concern of building trust in disadvantaged neighbourhoods and avoiding the potentially negative effects that ethnic diversity may have on trust, there are theoretical reasons for paying attention to the intervening mechanisms of institutional and generalized trust 
in this particular context. Theoretically, the relationship between these two forms of trust is argued to go through the intermediate variable (the mediator) of perceived safety and security (Rothstein \& Stolle 2008). Perceived safety, as well as actual exposure to risk such as crime or poverty, is known to be unevenly distributed in the population, individually and also geographically. Now, if perceived safety is a key mechanism in how institutional trust generates generalized trust, it should be of particular interest to explore this relationship in the context of a segregated and disadvantaged neighbourhood, in which inhabitants are particularly exposed to insecurities. Though being a central theoretical component, perceived safety is seldom included in empirical models studying the relationship between institutional trust and generalized trust. There are exceptions (Delhey \& Newton 2003; Uslander 2013), though they do not include it as a mediator. By including perceptions of safety, measured as crime-related insecurity, as an intermediating variable in our models, we may not only gain a more nuanced understanding of the trajectories of generalized trust, but also test these theoretical propositions, and how they relate to context.

In this article we demonstrate that the mechanisms behind the relationship between institutional trust and generalized trust differ between the segregated neighbourhood that we study and the population of the city. We give evidence of moderated mediation, meaning that a factor (crimerelated insecurity) that mediates the relationship between institutional trust and generalized trust plays a different role depending on neighbourhood context. By including perceptions of safety as a mediating variable in our model, we are able to show that in the segregated, diverse and disadvantaged neighbourhood trust in institutions, and particularly in government institutions, is associated with crime-related insecurity, which in turn leads to generalized trust. In the city as whole there is no such path; however, there is a stronger direct effect of institutional trust on generalized trust as well as from crime-related insecurity to generalized trust. Our results further suggest that a sample from the general population may hide contextual differences in terms of context-specific relational mechanisms. This is a crucial lesson if we want to learn more about how trust can be built.

The rest of the article consists of four sections, structured as follows. Firstly, we theorize about the relationship between institutional trust and generalized trust, both in general and in segregated and disadvantaged areas, and pose hypotheses to be tested. The subsequent section deals with our methods and measurements. In the third section, the results from our structural equation models and hypothesis tests are presented. In the final, concluding section, we discuss the implications of our findings and relate them to earlier research. 


\section{Theory and Hypothesis Development}

In this article we are interested in the structural relation between institutional trust (legal and government institutions) and generalized trust, and how this relationship is mediated by crimerelated insecurity in two different settings. We mean that to better understand how institutional and generalized trust are related, it is necessary to consider the role that trust in institutions plays in crime-related insecurity and the role that this insecurity in turn plays in explaining generalized trust. Furthermore, and central to the aim of this study, we argue that this indirect effect of institutional trust on generalized trust should be more evident in segregated and disadvantaged areas than in the norm society. This is the case because insecurities are more significant to most people living in such areas, and in that sense these residents are more dependent on wellfunctioning, trustworthy institutions. In what follows we start with a brief introduction to the concept of generalized trust and its relation to ethnic diversity. Then we develop our theoretical model by presenting hypotheses for each variable relation (path) of interest.

Generalized trust is considered a fundamental asset of a vital society, and the academic literature dealing with this topic is growing rapidly. There is a vast literature connecting generalized trust to efficient market economies (Kosfeld et al. 2005), well-functioning public institutions (Rothstein \& Stolle 2008), welfare state support (Bergh \& Bjørnskov 2014; Daniele \& Gey 2015), collective problem solving (Ostrom 1990) and health and well-being (Barefoot et al. 1998; Nyqvist et al. 2012). Though there is widespread agreement that trust is an essential asset for societies as well as individuals, there is still disagreement, and lack of clarity, concerning the mechanisms behind trust. Recent research has started to explore these relationships in greater detail. A growing number of studies focus on explaining the institutional trust and generalized trust of different groups in society, most notably immigrants (Kumlin \& Rothstein 2010; de Vroome et al. 2013; Dinesen 2013).

The focus on immigrants as a group and ethnic diversity as an independent variable has gained momentum since the publication of Putnam's (2007) oft-cited article, 'E pluribus unum: diversity and community in the twenty-first century', which addresses the relationship between ethnic diversity and trust. With data from the United States, Putnam (2007) showed that ethnic diversity is likely to weaken social cohesion in terms of generalized trust, and that it instead breeds feelings of threat. Ethnic diversity not only generates lower trust levels among the minority but it also seems to suppress generalized trust among the majority population when they are living in diverse neighbourhoods (Alesina \& La Ferrara 2002; Stolle et al. 2008). Thus, low trust may be understood as being a contextual effect of this kind of area. It is important to note that most research indicating such a link is from the U.S., and the result from a cross-national study in Europe does not convincingly support a general relationship between ethnic diversity and 
generalized trust (Hooghe et al. 2009; though see Dinesen \& Sønderskov 2012 regarding the Danish context). In a time when it is assumed that European countries are likely to be experiencing greater cultural and ethnic diversity (Hooghe et al. 2009, 199) and when decreasing trust levels are a widespread concern, this debate has solicited a lot of attention from policy actors as well as researchers.

In the context of decreasing trust and a particular vulnerability in this regard for certain groups and social contexts, there is a need to consider means of restoring trust. To establish and maintain fair and trustworthy institutions seem particularly crucial in this regard (Hooghe \& Stolle 2003; You 2012). However, in the particular context of a segregated, ethnically diverse and disadvantaged neighbourhood (henceforth referred to as a segregated neighbourhood), the individuals' generalized trust may be shaped differently than in society at large (Kumlin \& Rothstein 2010), in particular concerning the role that institutional trust has in shaping generalized trust, an argument that we will develop further below. In developing our hypotheses, we take our starting point in the more general research on the relationship between institutional trust and generalized trust.

\section{The Relationship Between Institutional Trust and Generalized Trust?}

At the societal level, there are two main explanatory theories, which differ in their assumptions concerning the causal relationship between institutional trust and generalized trust. The social capital theory (Putnam 2000) holds that membership and engagement in civil society organizations generates generalized trust, which in turn is fundamental for well-functioning democratic institutions. However, the connection between membership of organizations and generalized trust has received weak support (Delhey \& Newton 2003, 98; Rothstein \& Stolle 2008, 442). The relationship is also theoretically questionable, as the trust developed through organizational life is as likely particular as general, thus generating bonding rather than bridging social capital (Newton 2001; Putnam 2007; Rothstein \& Stolle 2008).

During the last decade, an alternative institution-centred approach has gained in strength, which argues for a reverse relationship, where well-functioning institutions generate generalized trust (Hall 1999; Rothstein \& Stolle 2008; Kumlin \& Rothstein 2010; You 2012). Stable and trustworthy institutions make it easier for individuals to act trustworthily towards each other (Newton 2007). Of particular importance in this respect are institutions of law and order, as their role is to detect, stop or punish those who do not obey the common laws, and so who are not to be trusted (Rothstein \& Stolle 2008, 445). If people perceive these institutions as well functioning and fair, they are likely to perceive society to be safer and more secure, as well as to believe that most people have reason to behave honestly, and consequently that most people can be trusted (Rothstein \& Stolle 2008, 445-446). The causal underpinnings of this hypothesis have also lately 
been tested empirically with longitudinal data form Denmark (Sønderskov \& Dinesen 2015) showing that the effect goes from institutional trust to generalized trust. As will be further argued in the next section, we focus particularly on legal and government institutions (for a similar specification of institutional trust, see Rothstein \& Stolle 2008), and as a consequence, we pose the following hypothesis about the relationship between institutional and generalized trust:

H1: Trust in legal and government institutions is positively associated with generalized trust.

Crime-Related Insecurity as a Mediating Variable Between Institutional and Generalized Trust

Several theoretical propositions consider safety or crime-related insecurity as a mediating variable between institutional trust and generalized trust as well as between diversity and generalized trust. The main argument for political institutions generating generalized trust, as stated above, is that they may bring about a safer society and law-abiding behaviours (Rothstein \& Stolle 2008). Trust appears to be greater when levels of public safety are high, and when people believe that social conflicts are not acute, while the experience of anxiety and fear of others breeds mistrust (Delhey \& Newton 2003, 111; Putnam 2007). It is therefore suggested that institutions may neutralize or prevent uncertainty by creating rules and norms which make interaction more predictable and which stimulate trustworthy behaviour, while obstructing behaviour that breaks those rules.

While these arguments are primarily connected to legal institutions, there are other arguments that connect crime-related insecurity to trust in government. One such argument is that crime-related insecurity is not necessarily primarily related to crime risk, but rather to the uncertainties of modern life, deriving from developments such as the individualization of risk, globalization and an increasing plurality of values (Holloway \& Jefferson 1997; Walklate 1998; Elchardus et al. 2008; Cops 2010). These ambiguous uncertainties may be projected as the more tangible fear of crime (Giddens 1991; Holloway \& Jefferson 1997). This means that trust in government could also neutralize crime-related insecurities.

In the same vein, democratic and welfare systems may build trust by neutralizing uncertainty and anxiety in a broader perspective. Hummelsheim et al. (2011) showed that a higher level of social expenditure and a higher degree of decommodification of social welfare policy are correlated with lower crime-related insecurity. The authors have suggested that these policy measures neutralize public insecurity and social anxiety (Hummelsheim et al. 2011, 337), which are powerful forces driving mistrust (Patterson 1999, 190). Their argument is supported by studies showing that welfare systems with universal principles are more likely to have trusting inhabitants (Rothstein \& Stolle 2008), as are countries with greater economic equality (Uslaner 2000; Newton 2007). 
The political system then signals that fairness and equality (or equal treatment) are values represented by the majority of the population. Since people tend to infer from the representatives of institutions to people in general this translates into generalized trust (Dinesen 2013, 116). Thus, we expect that trustworthy legal as well as government institutions may generate generalized trust both directly (H1) and indirectly through perceived safety. On the basis of these arguments, we pose the following three hypotheses:

H2: Trust in legal and government institutions is negatively related to crimerelated insecurity.

H3: Crime-related insecurity is negatively associated with generalized trust.

H4: There is an indirect effect from trust in legal and government institutions to generalized trust through crime-related insecurity.

\section{Segregated, Ethnically Diverse and Disadvantaged Neighbourhoods as a Critical Case}

We argue that it is not necessarily diversity per se that harms generalized trust (van der Meer \& Tolsma 2014), but diversity coupled with segregation (socioeconomically, ethnically and residentially), when the minority group is geographically segregated from the majority group, which limits the opportunities for contact between groups (Uslaner 2006; Stolle et al. 2013). Democratic institutions may play a more crucial role in segregated neighbourhoods for two reasons. First, the population of this kind of neighbourhood is not only residentially segregated from the majority population; they are also more likely to stand outside of society in terms of being unemployed, and substantially more likely to have immigrated. (For the neighbourhood characteristics of our sample, see Table 1). In this situation of relative exclusion, political institutions may signal the values of the majority population and thereby the trustworthiness of the society (Kumlin \& Rothstein 2010). Second, the indirect effect of trustworthy institutions through crime-related insecurity is likely to be more substantial in such segregated neighbourhoods. As the inhabitants face greater risks and are exposed to more disorder, they are also more dependent on the efficacy and fairness of the legal institutions as well as on the intentions of the political institutions. Indeed, trust in institutions and in the police has been shown to play a particularly crucial role for perceived safety in disadvantaged neighbourhoods (Persson 2013). In addition, the sense of powerlessness, common in neighbourhoods with high levels of crime, vandalism, graffiti, danger, noise and drugs, has been shown to amplify the effect of neighbourhood disorder on mistrust (Ross et al. 2001). Thus, we suggest that trustworthy institutions may not only reduce the level of disorder and risk but they may also have the capacity to reduce crime-related insecurity and powerlessness by signalling the values underpinning the 
society. Based on these arguments, we contend that trust in institutions is more important for reducing crime-related insecurity in segregated neighbourhoods than in general society, and therefore pose the following hypothesis:

H5: The indirect effect of trust in legal and government institutions (through crimerelated insecurity) on generalized trust is stronger in segregated neighbourhoods than in the surrounding (norm) society.

\section{Control Variables}

As control variables, we include some familiar concepts in research on institutional and generalized trust, both in general terms and related specifically to ethnic diversity and disadvantaged neighbourhoods. We include respondent age, education level, employment status, ethnic origin and social capital (voluntary association engagement), since these have been examined and shown to correlate with both institutional and generalized trust (Kumlin \& Rothstein 2010; Gijsberts et al. 2012; de Vroome et al. 2013) and crime-related insecurity (Persson 2013). These control variables also make it possible to better sort out the independent effect of neighbourhood from its individual structural characteristics (Gijsberts et al. 2012).

\section{Method}

\section{Design and Population}

Most research on this topic uses random samples from a population (a country or multiple countries) as survey design (e.g. Delhey \& Newton 2003, 2005; Kumlin \& Rothstein 2010; Dinesen \& Sønderskov 2012; Kokkonen et al. 2014). The strength of such an approach is statistical generalizability. While giving a representative picture of the general society, such a design may, however, mask interesting differences in certain subgroups of the population, due to low power and lack of contextualization. For these reasons we aim to complement such studies by utilizing a survey design where we focus on a well-known segregated neighbourhood in a city in Sweden and compare that sample with a random sample from the city representing the general population or the norm society, as would have been the case in most other research on the topic at hand. An obvious weakness with our design is that we cannot statistically generalize beyond our single neighbourhood and the city of Örebro. However, as is shown below, we believe that our case of Örebro and Vivalla shares futures with other cities and neighbourhoods in Sweden and that our sample may also be substantially representative of other European cities. This is 
because the issue of segregated neighbourhoods such as the one described here pertains in many other countries.

The empirical material comes from Örebro, a medium-sized city population-wise in central Sweden with approximately 140,000 inhabitants. The city could be considered a typical Swedish city and has a demographic composition comparable to other medium-sized Swedish cities. Like many Swedish cities of comparable size, it has ethnic and residential segregation. The neighbourhood investigated in this study, Vivalla, is a socioeconomically disadvantaged neighbourhood which is geographically segregated and considered the most problematic neighbourhood in Örebro in terms of crime and disorder (Örebro Police 2009). A random sample from the population of the city of Örebro (the Vivalla area excluded) is used as the comparison reference point representing the norm society.

\section{Contextualizing the Neighbourhood}

In 2011 (the year following this study), the neighbourhood of Vivalla had 6823 inhabitants. During the last decade the neighbourhood has had a steadily increasing population, and the percentage of the inhabitants with foreign backgrounds has steadily risen (an average of $74.7 \%$ in 2011 compared to 52.6\% in 2003) (Örebro Municipality 2012). This increase is explained by the high turnover of inhabitants, with a relatively large number of 'native Swedes' moving away from the neighbourhood at the same time as more people with foreign backgrounds have moved into the neighbourhood. See Table 1 for a listing of the demographic characteristics of the inhabitants of Vivalla and Örebro in general.

Table 1. Neighbourhood characteristics (Örebro Municipality 2010)

\begin{tabular}{|l|l|c|c|c|c|c|c|}
\hline & \% with... & $\begin{array}{c}\text { Higher } \\
\text { education }\end{array}$ & $\begin{array}{c}\text { Education } \\
<9 \text { years }\end{array}$ & $\begin{array}{c}\text { Open } \\
\text { unemployment } \\
\text { (age 18-24 years) }\end{array}$ & $\begin{array}{c}\text { Open } \\
\text { unemployment } \\
\text { (age 18-64 years) }\end{array}$ & $\begin{array}{c}\text { Foreign } \\
\text { birth }\end{array}$ & $\begin{array}{c}\text { Foreign } \\
\text { background }\end{array}$ \\
\hline \multirow{3}{*}{ Vivalla } & Women & 7.7 & 25.4 & 12.8 & 14.0 & 52.4 & 74.8 \\
\cline { 2 - 9 } & Men & 9.6 & 19.6 & 11.0 & 16.3 & 50.3 & 74.5 \\
\cline { 2 - 9 } & Total & $\mathbf{8 . 7}$ & $\mathbf{2 2 . 5}$ & $\mathbf{1 1 . 9}$ & $\mathbf{1 5 . 1}$ & $\mathbf{5 1 . 3}$ & $\mathbf{7 4 . 7}$ \\
\hline \multirow{3}{*}{ Örebro } & Women & 30.0 & 4.6 & 4.9 & 3.9 & 15.1 & 20.7 \\
\cline { 2 - 9 } & Men & 21.1 & 4.6 & 6.0 & 4.4 & 14.8 & 20.8 \\
\cline { 2 - 9 } & Total & $\mathbf{2 5 . 5}$ & $\mathbf{4 . 6}$ & $\mathbf{5 . 4}$ & $\mathbf{4 . 1}$ & $\mathbf{1 5 . 0}$ & $\mathbf{2 0 . 7}$ \\
\hline
\end{tabular}

Unemployment (31 October 2011) is according to the definition of the Swedish Employment Office.

The neighbourhood was founded around 1967-1970. At that time, apartment housing was being built on a large scale in the suburban areas of Sweden, which in Vivalla's case resulted in the 
construction of a homogeneous neighbourhood dominated by small rental apartments. Before long, the neighbourhood began to be perceived and described as a 'problem area', and it has since come to be associated with negative attributes such as criminality, lack of safety, social problems, a high density of immigrants and uniform apartments (Örebro Police 2009), many of which are structural challenges that Vivalla faces. However, as Lilja (2008) noted, it is important to remember that the external images of a marginalized place may often be more negative than the image held by its inhabitants who have memories, life experiences and a connection to the place.

Vivalla is the neighbourhood in Örebro with the most concerns about criminality (Örebro Police 2009). The most alarming crime statistics pertain to violence against women in intimate relationships ${ }^{2}$ and muggings. Both crimes are about three to five times more frequent in Vivalla than in Örebro in general. Other crimes, which are about twice as common in Vivalla as in Örebro, are physical assault outdoors, moped theft and drug offences (Örebro Police 2009). According to the police, there is also a serious problem with the recruitment of young men into criminal gangs as a consequence of the structural disadvantages of the neighbourhood (Örebro Police 2009). During the last year the neighbourhood has figured regularly in national media as the community faces problems with inhabitants leaving to join the Islamic State, and with recruitment from the neighbourhood.

\section{The Questionnaire}

The questionnaire was sent to 1000 respondents in the second half of 2010 (Örebro, 400; Vivalla, 600). The weighted sample size in Örebro vis-à-vis Vivalla was due to a concern about a lower response rate in Vivalla (Feskens et al. 2006; Feskens et al. 2007). To avoid the risk of dramatically unequal sample sizes for statistical comparisons, this weighting in favour of Vivalla was made. The questions were in Swedish, but respondents could reply in English via the Internet. The reminders also included options for other languages (Somali and Arabic). Four reminders were sent. The net ${ }^{3}$ response rate was $43.6 \%$ (Örebro, 61.8\%; Vivalla, 30.8\%), ${ }^{4}$ resulting in a sample size of $\mathrm{N}=403$ (Örebro, 237; Vivalla, 167). The response pattern is similar to that of studies in other countries (Feskens et al. 2006; Feskens et al. 2007). The lower response rate in Vivalla was arguably caused by the rapid turnover in its population, as well as by language barriers (de Vroome et al. 2013).

To control for bias in the Vivalla sample due to non-responses, three variables of individual characteristics (gender, employment and foreign birth) were compared with the municipal data set. No significant differences were revealed. ${ }^{5}$ The numbers of women and men are similar. The portion of respondents born abroad in this data set is $49.1 \%$ in Vivalla and $11.1 \%$ in Örebro as a whole, compared to $50.1 \%$ and $14.5 \%$, respectively, in the municipal data set for 2010 . 
Concerning employment, the number of respondents in this sample describing themselves as unemployed was 9.1\% in Vivalla and $1.7 \%$ in Örebro, compared to $9.3 \%$ and 5.3\%, respectively, in the municipal data set from the same year. Note that the Vivalla respondent percentages are closer to those in the municipal data set than are the Örebro respondent percentages, concerning unemployment and foreign birth. This difference may partly be explained by the fact that the sample used in this study is from the city of Örebro, whereas the municipal statistics cover a wider area. To conclude, this test shows no considerable bias due to non-responses.

\section{Measurements and Descriptive Statistics}

In our measurement and structural models, we have four variables of main interest and five control variables. As there are many different types of democratic institutions, both theory and measurement considerations often suggest that we should distinguish between these, that is to say, have multiple measures of trust in different institutions (Rothstein 2001; Rothstein \& Stolle 2008, 444). In our case, we find it appropriate to differentiate between trust in government and the democratic system (the representative side), on the one hand, and trust in legal institutions, on the other. Our theoretical argument suggests that legal institutions have a particular role in constructing and maintaining an ordered society where people may feel safe and put trust in one another. Trust in the representative side of government is taken to signal the perception of the values and intentions of the majority society, such as fairness or equality. Trust in government is a latent variable and is measured by three items: trust in state government, national parliament and local parliament. Trust in legal institutions is a latent variable and concerns trust in the legal system (courts) and the police. The trust questions were posed in terms of the degree to which the respondents have confidence that the listed institutions do a good job (replicated from the wording in the Swedish SOM surveys, e.g. Rothstein 2001). Crime-related insecurity is a latent variable consisting of three items that capture a general notion of safety in society (cf. Elchardus et al. 2008; Cops 2010): 'At night, you have to be particularly careful when out in the streets.' 'A burglar alarm is essential nowadays.' 'It is not safe enough to let our children play outside alone.' When perceived safety has been included in models for explaining generalized trust, the variable used has generally been the standard proposition for measuring fear of crime (Delhey \& Newton 2003; Uslaner 2013). However, we used a concept that captures a more general concern about crime and safety rather than just fear of specific crimes or fear of being out late at night (Elchardus et al. 2008). Fear of crime is typically linked to specific situations and therefore may be significant in strength but occur infrequently (Farrall \& Gadd 2004). Because crime-related insecurity is less specific than fear of crime, the concept does not have the functional aspect that is inherent with fear of crime (Jackson \& Gray 2010). Generalized trust is measured through the widely used oneitem measure: 'Generally speaking, to what degree would you say that most people can be trusted?'. All these items were measured with a fully anchored (labelled) five-point Likert scale 
(ranging from 1 = very low to 5 = very high). The five control variables are education level (none, primary school, secondary school, higher education), age, unemployed status, Non-European origin and social capital in the form of the level of engagement in voluntary associations.

In Table 2 we present descriptive statistics and model fit statistics for the measurement model. The latent variables show good convergent validity and unidimensionality, with a Cronbach's alpha of $>0.7$ and average variance extracted $>0.5$ (Fornell \& Larcker 1981). Since the square root of the average variance extracted does not fall below the highest correlation between variables in the model (Table 3), discriminant validity is assured (Fornell \& Larcker 1981). Model fit statistics for the measurement model show acceptable to good fit to data (Hair et al., 2010) ${ }^{6}$. Comparing the measurements for the two groups (Örebro and Vivalla) shows almost identical measurement properties (untabulated analyses). A correlation matrix of variables is displayed in Table 3.

A separate confirmatory factor analysis (CFA) of the two types or dimensions of institutional trust clearly points in favour of separating them. The one-factor model has significantly worse model fit (chi-square 187.732; Df 5) than the two-factor model (chi-square 18.655; Df 4). Furthermore, constraining the covariation between the two factors to one as compared to estimating it freely results in significantly worse model fit $(p=0.01)$ for one degree of freedom difference. These tests clearly show that there are two separate forms of institutional trust rather than one coherent measure of institutional trust and that discriminate validity is assured (Bagozzi et al. 1991). The latent variables have for natural reasons (they are what they are) few indicators, and as few as two in the case of legal institutions. This means that the latent variable legal institutions is unidentified in isolation in a CFA, and is dependent upon being included in a wider nomological network such as the CFA made above or as in Table $2 .^{7}$

Except for one of the dichotomous variables (unemployment), descriptive statistics show no severe signs of non-normality. Generally, missing values on the item level are few, ranging from $0 \%$ to $4 \%$ per variable. Comparing list-wise means and correlations with expectation maximum means and correlations reveals no differences. To preserve statistical strength, we used the full information maximum likelihood estimation technique, which is a powerful method for handling missing values incorporated in most structural equation modelling packages (Hair et al. 2010); simulation studies have demonstrated that it outperforms other methods for handling missing values such as list-wise deletion and mean replacement (Enders 2001). 
Table 2. Measurement properties

\begin{tabular}{|c|c|c|c|c|c|c|c|}
\hline & Org. N & $\begin{array}{l}\text { Rang } \\
\text { e }\end{array}$ & Mean & $\begin{array}{l}\text { Std. } \\
\text { dev. }\end{array}$ & $\begin{array}{l}\text { Skewnes } \\
\text { s }\end{array}$ & $\begin{array}{l}\text { Kurtosi } \\
\text { s }\end{array}$ & $\begin{array}{l}\text { Factor } \\
\text { loading }\end{array}$ \\
\hline \multicolumn{8}{|c|}{ Trust in government $($ Alpha $=0.852 ; \mathrm{AVE}=0.676)$} \\
\hline State government & 393 & $1-5$ & 3.090 & 1.143 & -0.309 & -0.704 & $0.879 \mathrm{~F}$ \\
\hline National parliament & 393 & $1-5$ & 3.080 & 1.106 & -0.379 & -0.618 & 0.942 \\
\hline $\begin{array}{l}\text { Local (municipal) } \\
\text { government }\end{array}$ & 390 & $1-5$ & 2.710 & 1.002 & -0.104 & -0.510 & 0.648 \\
\hline \multicolumn{8}{|c|}{ Trust in legal institutions (Alpha $=0.838 ;$ AVE $=0.731)$} \\
\hline Legal system & 386 & $1-5$ & 3.280 & 1.050 & -0.558 & -0.258 & $0.962 \mathrm{~F}$ \\
\hline Police & 388 & $1-5$ & 3.450 & 1.001 & -0.641 & 0.057 & 0.748 \\
\hline \multicolumn{8}{|c|}{ Crime-related insecurity $($ Alpha $=0.781 ;$ AVE $=0.537)$} \\
\hline $\mathrm{A}$ & 395 & $1-5$ & 4.100 & 1.057 & -1.191 & 0.830 & $0.630 \mathrm{~F}$ \\
\hline $\mathrm{B}$ & 391 & $1-5$ & 3.320 & 1.209 & -0.320 & -0.750 & 0.760 \\
\hline $\mathrm{C}$ & 392 & $1-5$ & 3.320 & 1.272 & -0.341 & -0.919 & 0.808 \\
\hline Generalized trust & 397 & $1-5$ & 3.470 & 1.090 & -0.682 & -0.332 & . \\
\hline Education level & 395 & $1-4$ & 3.150 & 0.809 & -0.607 & -0.372 & . \\
\hline Age & 396 & $17-88$ & 47.179 & 16.541 & -0.068 & -1.052 & . \\
\hline Non-European (0:1) & 399 & $0-1$ & 0.231 & 0.422 & 1.284 & -0.353 & . \\
\hline Unemployed (0:1) & 399 & $0-1$ & 0.048 & 0.213 & 4.265 & 16,268 & . \\
\hline \multirow[t]{2}{*}{ Social capital } & 394 & $1-5$ & 2.700 & 1.316 & 0.168 & -1.112 & . \\
\hline & & & & & & & $\begin{array}{l}\text { All loadings } \\
\mathrm{p}=0.000\end{array}$ \\
\hline \multicolumn{8}{|c|}{$\begin{array}{l}\text { Model fit statistics: chi-square 99.071***; Df 47; CFI 0.970; RMSEA 0.052 (Pclose 0.369). } \\
\mathrm{N}=403 . \text { Std. dev. = standard deviation. Full information maximum likelihood estimations. }\end{array}$} \\
\hline \multicolumn{8}{|c|}{ F after factor loading means fixed to 1; Alpha = Cronbach’s alpha; AVE = average variance extracted. } \\
\hline
\end{tabular}

Table 3. Correlation matrix

\begin{tabular}{|l|l|l|l|l|l|l|l|l|l|}
\hline & 1 & 2 & 3 & 4 & 5 & 6 & 7 & 8 & 9 \\
\hline 1 Trust in government & $\mathbf{0 . 8 2 2}$ & & & & & & & & \\
\hline 2 Trust in legal institutions & 0.646 & $\mathbf{0 . 8 5 4}$ & & & & & & & \\
\hline 3 Crime related insecurity & -0.298 & -0.234 & $\mathbf{0 . 7 3 2}$ & & & & & & \\
\hline 4 Generalized trust & 0.303 & 0.279 & -0.432 & - & & & & & \\
\hline 5 Education level & 0.132 & 0.076 & -0.343 & 0.188 & - & & & & \\
\hline 6 Age & 0.043 & 0.010 & 0.095 & 0.119 & -0.198 & - & & & \\
\hline 7 Non-European & 0.112 & -0.014 & 0.178 & -0.281 & -0.166 & -0.139 & - & & \\
\hline 8 Unemployed & -0.119 & -0.055 & 0.037 & -0.136 & -0.158 & -0.074 & 0.119 & - & \\
\hline 9 Social capital & 0.239 & 0.135 & -0.048 & 0.107 & 0.054 & -0.005 & 0.141 & 0.22 & - \\
\hline 10 Area/sample (Vivalla=1) & -0.104 & -0.039 & 0.212 & -0.257 & -0.264 & -0.070 & 0.411 & 0.171 & -0.02 \\
\hline
\end{tabular}

All correlations above $+/-0.104$ are significant at $\mathrm{p}<0.05$ (two-tailed). Bold diagonals are the square root of average

variance extracted. $\mathrm{N}=403$. 


\section{Structural Model Results}

In this section we present the formal statistical tests of our structural model and also graphically present the structural model results. In the following section we discuss the results and relate our findings to theory and the wider literature. The structural models are estimated with covariancebased (maximum likelihood) structural equation modelling.

The theoretical argument and empirical design of this article concern differences in structural relations between the two samples, a random sample from the city of Örebro and a focused sample from a segregated area in the city, called Vivalla. In Table 4, we present results from a multigroup structural analysis (Hair et al. 2010), splitting the analysis of the two samples. In untabulated analyses we first fitted one model on the two combined samples and included the type of sample (Örebro/Vivalla) as a dichotomous endogenous variable. The type of sample had no effects (std $B=0.069$ to crime-related insecurity and std $B=-0.073$ to generalized trust) on the two exogenous variables in the model, showing that a subgroup analysis is appropriate for assessment of moderation (Sharma et al. 1981). In Model 1a, the results from the Örebro sample are presented, and in Model 1b, the results from the Vivalla sample. We used one-sided tests for statistical significance for all hypotheses, since they are directional, and used two-sided tests for the control variables, since no direction was specified (Cho \& Abe 2013), and present standardized regression weights in Table 4. In Table A1 of Appendix 1 we also disclose raw weights and standard errors.

Table 4. Structural regression models in the two samples

\begin{tabular}{|c|c|c|c|c|}
\hline \multirow[t]{2}{*}{ Multigroup by area } & \multicolumn{2}{|c|}{ Model 1a: Örebro $(\mathrm{N}=236)$} & \multicolumn{2}{|c|}{ Model 1b: Vivalla $(\mathrm{N}=167)$} \\
\hline & $\begin{array}{l}\text { To: Crime- } \\
\text { related } \\
\text { insecurity }\end{array}$ & $\begin{array}{l}\text { To: } \\
\text { Generalized } \\
\text { trust }\end{array}$ & $\begin{array}{l}\text { To: Crime- } \\
\text { related insecurity }\end{array}$ & $\begin{array}{l}\text { To: Generalized } \\
\text { trust }\end{array}$ \\
\hline \multicolumn{5}{|l|}{ From: } \\
\hline Trust in government & -0.066 & $0.249 * * *$ & $-0.559 * * *$ & 0.031 \\
\hline $\begin{array}{l}\text { Trust in legal } \\
\text { institutions }\end{array}$ & $-0.173 *$ & 0.060 & 0.140 & 0.154 \\
\hline $\begin{array}{l}\text { Crime-related } \\
\text { insecurity }\end{array}$ & . & $-0.407 * * *$ & . & $-0.244 * *$ \\
\hline \multicolumn{5}{|l|}{ Controls } \\
\hline Education level & $-0.337 * * *$ & -0.099 & $-0.177^{*}$ & 0.104 \\
\hline Age & 0.073 & $0.116^{*}$ & 0.062 & 0.089 \\
\hline Non-European & 0.072 & $-0.158 * *$ & $0.213^{*}$ & $-0.201 *$ \\
\hline Unemployed & -0.048 & -0.031 & -0.074 & -0.075 \\
\hline Social capital & 0.012 & 0.085 & 0.044 & 0.089 \\
\hline$R^{2}$ & 0.204 & 0.345 & 0.237 & 0.189 \\
\hline
\end{tabular}


In the Örebro sample, trust in government has a direct and positive effect on generalized trust, and trust in legal institutions ${ }^{8}$ has a direct and positive effect on general crime-related insecurity. Crime-related insecurity has a strong negative effect (std $B=0.401)$ on generalized trust. A test for an indirect effect of trust in legal institutions on generalized trust proves insignificant. To test for mediation we used bootstrapping (Preacher \& Hayes 2008; Zhao et al. 2010).

In the Vivalla sample, there is no evidence of statistically significant direct effects on generalized trust from the institutional trust variables; however, trust in government has a strong (std $B=$ 0.559) effect on crime-related insecurity that in turn affects generalized trust. Although the relationship between crime-related insecurity and generalized trust is weaker in the Vivalla sample, the bootstrap estimate of the indirect effect (mediation) of trust in government on generalized trust is positive (Boot $B=0.141$; S.E. $=0.059$ ) and significant within a $95 \%$ confidence interval (two-sided) (1000 bootstrap samples and bias corrected). This is a case of full mediation. There is a positive (std $B=0.165)$, although insignificant ( $\mathrm{p}=0.091$ ), direct effect between trust in government and generalized trust in the Vivalla sample when crime-related insecurity is removed from the model. Controlling for crime-related insecurity supresses that effect to almost zero (Table 4, Model 1b).

The mediation of crime-related insecurity for the relationship between institutional and generalized trust occurs in two steps. The mediation is dependent upon the relation between both (1) institutional trust and crime-related insecurity and (2) crime-related insecurity and generalized trust. It is interesting to note that the moderation (based on area) of this mediation results in two different patterns. That is to say, the mediation plays out differently in the two areas (Vivalla and Örebro). In the first instance (1) the effect is non-existent for trust in government and weak for trust in legal institutions in the Örebro sample, but very evident for trust in government (std B = 0.559) in Vivalla. In the second instance (2) the opposite is the case. The effect of crime-related insecurity on generalized trust is evident in both samples, but the effect is almost the double in Örebro (std B $=0.407$ vs 0.244 ). Thus, it is the first step of the mediation that explains the nonexisting indirect effect in the Örebro sample and the existing indirect effect in Vivalla. Crimerelated insecurity is crucial for generalized trust in both areas; however, in the Örebro area, crimerelated insecurity is not strongly enough associated with institutional trust.

The explained variance in the models is fairly good - ranging from $19 \%$ to $35 \%$ - and is on a comparative level with a recent study on the relationship between institutional and generalized trust (Sønderskov \& Dinesen 2015), and well above what has been reported in similar research with Swedish data (e.g. Rothstein 2001; Kumlin \& Rothstein 2010). Apart from education level and non-European origin, the control variables are not influential in adding to the explained variance of the models (Table 4). Education level decreases the perceived crime-related insecurity 
in both samples, and the effect is quite strong in the Örebro sample. Non-European origin lessens generalized trust in both samples and increases crime-related insecurity in the Vivalla sample, but not in the Örebro sample.

A number of additional tests were carried out to assess the hypothesized differences between the two independent samples. A z-value difference test (Paternoster et al. 1998) shows that the path co-efficient between trust in government and crime-related insecurity for the two samples is highly statistically different $\left(\mathrm{H}_{0}\right.$ : $\mathrm{b}-$ Vivalla $=\mathrm{b}-$ Örebro $)(\mathrm{z}=-3.51 ; \mathrm{p}<0.01)$, but not the difference in paths for the effect from crime-related insecurity to generalized trust $(z=-1.43 ; p>0.05)$ Monte Carlo estimation of the indirect effect (Selig \& Preacher 2008; MacKinnon et al. 2004) shows that the confidence intervals (95\%) of the indirect effects in the two samples do not overlap. Specifying the control variable education level as three dummy variables instead of a continuous variable does not substantially change any of the structural model results.

Relating back to our hypotheses and to highlight the results from the multigroup analysis, a graphical representation of the results in Figure 1 complements the textual summary. Hypothesis 1 , about the relation between institutional trust and generalized trust, gets partial support, since there is only an evident direct effect in Örebro and not in Vivalla. It is noteworthy that only trust in government and not trust in legal institutions has a direct effect in the sample from Örebro. Hypothesis 2 also gets support. Trust in legal institutions drives less crime-related insecurity in Örebro, and in Vivalla it is trust in government that has such an effect. Depending on the context, different institutions are important for reducing crime-related insecurity. Hypothesis 3 gains strong support. Crime-related insecurity is negatively related to generalized trust in both samples. Noteworthy is that the effect is almost double in Örebro compared to Vivalla. Hypothesis 4, about the indirect effect of institutional trust on generalized trust, is supported only in Vivalla, and thus, is also related to Hypothesis 5. This hypothesis states that the mediating role of crime-related insecurity should be more pronounced in the segregated, disadvantaged neighbourhood than in the Örebro sample. The results not only show that the mediating effect is stronger in the Vivalla sample, but that in the (random) sample of the city of Örebro there is no indirect effect from trust in government or legal institutions and in the segregated neighbourhood of Vivalla crime-related insecurity fully mediates the relation between trust in government institutions and generalized trust. The moderated mediation (H5) is thus not just about differences in degree or strength as stated in the hypothesis, but about differences in form (structure). 


\section{Figure 1}

Örebro (random sample)

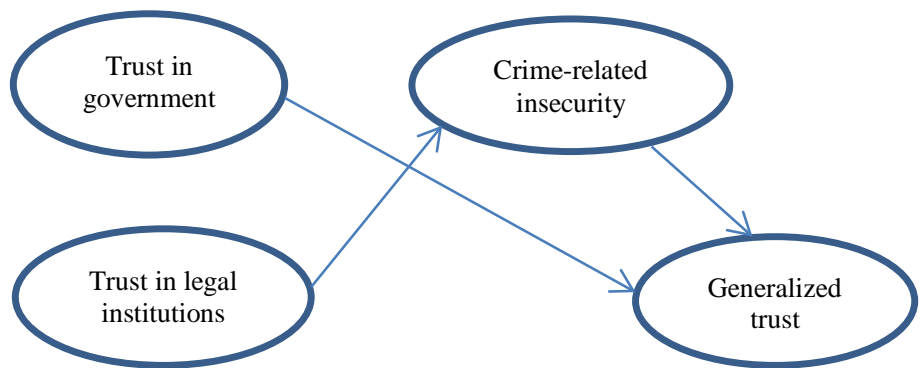

Vivalla (area within Örebro)

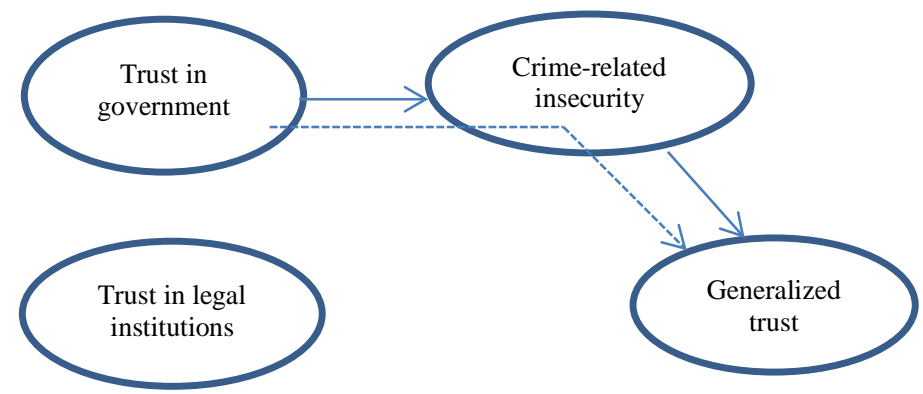

Figure 1. Graphical presentation of structural model results. Unbroken arrows denote (significant) direct effects and dotted arrows (significant) indirect effects.

\section{Discussion and Conclusions}

In this study we argue and show that neighbourhood context is important in explaining differences in how trust in institutions materializes into generalized trust. Our investigation first and foremost shows that in the city population of Örebro trust in government has a direct effect on generalized trust, whilst in the segregated and disadvantaged neighbourhood, the effect is indirect via reduced crime-related insecurity. The end result (i.e. its effect on variability in generalized trust) of having trusted government institutions is similar in the two samples, but the mechanism explaining this outcome is quite different. This is a crucial lesson, since levels of trust tend to vary between groups and tend to be lower in segregated, disadvantaged and multi-cultural neighbourhoods (Ross et al. 2001; Putnam 2007). It is thus crucial to learn more about how trust can be built within such particular contexts.

In the random sample of the city trust in government is not associated with crime-related insecurity, but in the segregated neighbourhood this connection is very strong. Thus, the workings and appearance of government to create trust are important for generalized trust in both contexts, but in the segregated neighbourhood the process is more intricate than the standard view suggests (e.g. Sønderskov \& Dinesen 2015). People in the segregated 
neighbourhood who trust political institutions at national and local levels perceive society to be less unsafe. This in turn spills over into a more general perception that people can be trusted.

It should be duly noted that safety (crime-related insecurity) is important for explaining generalized trust in the city population as well. The difference is that here the institutional trust variables are not associated with crime-related insecurity. In the population of the whole city, trust in government is instead directly related to generalized trust. Thus, while it is a common assumption, and empirically established, that the relationship goes from institutional to generalized trust (Sønderskov \& Dinesen 2015), or to some extent is positively reciprocal (Robbins 2012), our study highlights that the foundation for such an explanation may vary between groups and contexts. The relationship between government and legal institutions and generalized trust is not universal and not necessarily a direct (causal) relationship.

The mediation effect found in the Vivalla neighbourhood may therefore say something more fundamental and interesting about the relationship between trust in government institutions and generalized trust. The enhancement of a positive view on the state and politics makes inhabitants in these areas perceive society as less unsafe, and as a consequence, they are also more willing to expose themselves to vulnerability, that is, trust (Rousseau et al. 1998), when interacting with fellow citizens. This is exactly how Rothstein and Stolle (2008) have theorized the universal relationship between institutional and generalized trust. However, we find that this explanation holds true only for trust in government and not for trust in legal institutions, which according to the theory, would be the most expected (Rothstein \& Stolle 2008). We find that having a trusted political and democratic system is more important than having a trusted judicial system. ${ }^{9}$ Having trust in government institutions (or having trustworthy political institutions, if you like) seems to be even more fundamental to people in exposed areas. Their perception of the political system could be seen as reflecting their perception of the values and fairness of the system and the majority population (cf. Dinesen 2013), which affects how safe they perceive society to be and thus their tendency to trust people in general.

A possible interpretation of the finding that government institutions are more crucial than legal institutions is that other uncertainties have a greater effect on perceived safety, and in the next step, on generalized trust, than have crime-related uncertainties. People in these kinds of areas are more exposed to different kinds of risk (economic, social and crime), a cumulative uncertainty that may be canalized through the perception of the more tangible risks of crime (Elchardus et al. 2008). In the city population, trust in legal institutions lessens crime-related insecurity, but it does not spill over (indirect effect) into generalized trust. These findings add to our understanding of the role that institutional trust plays in creating generalized trust (Rothstein \& Stolle 2008; 
Sønderskov \& Dinesen 2015) and especially show the importance of this relationship for disadvantaged neighbourhoods.

Our study is not without limitations. We used cross-sectional data and cannot address causality directly, but are dependent upon theory (assumptions) for giving meaning to associations. Future research efforts should be directed at validating our theory and findings in other similar contexts and with experimental or longitudinal data. An advance with our study, however, is that we use structural equation modelling combining confirmatory factor analysis with estimations of multiple structural relations. Such a method has several advantages - in comparison with the more common use of additive indices and regression analysis - when employing a complex measurement and structural model in the form of latent variables and mediation. In comparison to other studies within our domain that use large cross-country or inter-country data sets, we have a relatively narrow and small sample. Instead, we have a sampling design that more directly focuses on a specific segregated, ethnically diverse and disadvantaged neighbourhood compared with a random sample of the city in which the area belongs. Our design has made it possible to show that the mechanisms of trust building may differ in different local contexts, and perhaps more crucially, that general-population samples may conceal such differences and create too noisy a sample for exploring the mechanisms of trust. Although our findings should be treated with some caution when it comes to generalizability, we believe that they raise crucial questions for future research to validate and extend further.

\section{Acknowledgements}

The authors would like to thank the three anonymous referees for their thoughtful and constructive comments on an earlier version of this text. We would also like to acknowledge the Örebro Police, who financed the administration of the survey. 


\section{References}

Alesina, A. \& La Ferrara, E. 2002. 'Who Trusts Others?’ Journal of Public Economics, 85, 207-234.

Bagozzi, R. P., Yi, Y. \& Phillips, L. W. 1991. 'Assessing Construct Validity in Organizational Research', Administrative Science Quarterly, 36, 421-458.

Barefoot, J. C., Maynard, K. E., Beckham, J. C., Brummett, B. H., Hooker, K. \& Siegler, I. C. 1998. 'Trust, Health, and Longevity', Journal of Behavioral Medicine, 21, 517-526.

Bergh, A. \& Bjørnskov, C. 2014. 'Trust, Welfare States and Income Equality: Sorting out the Causality’, European Journal of Political Economy, 35, 183-199.

Cho, H. C. \& Abe, S. 2013. 'Is Two-tailed Testing for Directional Research Hypotheses Tests Legitimate?’ Journal of Business Research, 66, 1261-1266.

Cops, D. 2010. 'Socializing into Fear: The Impact of Socializing Institutions on Adolescents' Fear of Crime', Young, 18, 385-402.

Daniele, G. \& Geys, B. 2015. 'Interpersonal Trust and Welfare State Support', European Journal of Political Economy, 39, 1-12.

Delhey, J. \& Newton, K. 2003. 'Who Trusts? The Origins of Social Trust in Seven Societies’, European Societies, 5, 93-137.

Delhey, J. \& Newton, K. 2005. 'Predicting Cross-National Levels of Social Trust: Global Pattern or Nordic Exceptionalism?’ European Sociological Review, 21, 311-327.

Dinesen, P. T. 2013. 'Where You Come From or Where you Live? Examining the Cultural and Institutional Explanation of Generalized Trust Using Migration as a Natural Experiment', European Sociological Review, 29, 114-128.

Dinesen, P. T. \& Sønderskov, K. M. 2012. 'Trust in a Time of Increasing Diversity: On the Relationship Between Ethnic Heterogeneity and Social Trust in Denmark from 1979 until Today’, Scandinavian Political Studies, 35, 273-294.

Elchardus, M., De Groof, S. \& Smits, W. 2008. 'Rational Fear or Represented Malaise: A Crucial Test of Two Paradigms explaining Fear of Crime', Sociological Perspectives, 51, 453471. 
Enders, C. K. 2001. 'The Performance of the Full Information Maximum Likelihood Estimator in Multiple Regression Models with Missing Data’, Educational and Psychological Measurement, 61, 713-740.

Farrall, S. \& Gadd, D. 2004. 'Research Note - The Frequency of the Fear of Crime', British Journal of Criminology, 44, 127-132.

Feskens, R., Hox, J., Lensvelt-Mulders, G. and Schmeets, H. 2006. 'Collecting Data Among Ethnic Minorities in an International Perspective’, Field Methods, 18, 284-304.

Feskens, R., Hox, J., Lensvelt-Mulders, G. \& Schmeets, H. 2007. 'Nonresponse among Ethnic Minorities: A Multivariate Analysis’, Journal of Official Statistics, 23, 387-408.

Fornell, C. \& Larcker, D. 1981. 'Evaluating Structural Equation Models with Unobservable Variables and Measurement Error’, Journal of Marketing Research, 18, 39-50.

Forrest, R. \& Kearns, A. 2001. 'Social Cohesion, Social Capital and the Neighbourhood', Urban Studies, 38, 2125-2143.

Gesthuizen, M., Van der Meer, T. \& Scheepers, P. 2009. 'Ethnic Diversity and Social Capital in Europe: Tests of Putnam's Thesis in European Countries', Scandinavian Political Studies, 32, 121-142.

Giddens, A. 1991. Modernity and Self-Identity. Self and Society in the Late Modern Age. Cambridge: Polity.

Gijsberts, M., van der Meer, T. \& Dagevos, J. 2012. 'Hunkering Down’ in Multi-Ethnic Neighbourhoods? The Effects of Ethnic Diversity on Dimensions of Social Cohesion', European Sociological Review, 28, 527-537.

Hair, J. F., Black, W. C., Babin, B. J., Anderson, R. E. \& Tatham, R. L., 2010. Multivariate Data Analysis (7th ed.). Upper Saddle River, NJ: Pearson Prentice Hall.

Hall, P. A. 1999. 'Social Capital in Britain', British Journal of Political Science, 29, 417-461.

Holloway, W. \& Jefferson, T. 1997. 'The Risk Society in an Age of Anxiety: Situating Fear of Crime', The British Journal of Sociology, 48, 255-266.

Hooghe, M., Reeskens, T., Stolle, D. \& Trappers, A. 2009. 'Ethnic Diversity and Generalized Trust in Europe: A Cross-National Multilevel Study', Comparative Political Studies, 42, 198223. 
Hooghe, M. \& Stolle, D., eds. 2003. Generating Social Capital: Civil Society and Institutions in Comparative Perspective. New York: Palgrave Macmillan.

Hummelsheim, D., Hirtenlehner, H., Jackson, J. \& Oberwittler, D. 2011. 'Social Insecurities and Fear of Crime: A Cross-National Study on the Impact of Welfare State Policies on Crimerelated Anxieties', European Sociological Review, 27, 327-345.

Jackson , J. \& Gray, E. 2010. 'Functional Fear and Public Insecurities about Crime’, British Journal of Criminology, 20, 1-22.

Kokkonen, A., Esaiasson, P. \& Gilljam, M. 2014. 'Migration-based Ethnic Diversity and Social Trust: A Multilevel Analysis of How Country, Neighbourhood and Workplace Diversity Affects Social Trust in 22 Countries', Scandinavian Political Studies, 37, 263-300.

Kosfeld, M., Heinrichs, M., Zak, P. J., Fischbacher, U. \& Fehr, E. 2005. 'Oxytocin Increases Trust in Humans', Nature, 435, 673-676.

Kumlin, S. \& Rothstein, B. 2010. 'Questioning the New Liberal Dilemma: Immigrants, Social Networks, and Institutional Fairness', Comparative Politics, 43, 63-80.

Langer, G. 2003. 'About Response Rates - Some Unsolved Questions’, Public Perspective, May/June, 16-18.

Lilja, E. 2008. 'Den meningsfulla förorten - Statsrum och offentlig plats i en segregerad stad', in Forsell, H., ed., Den kalla och varma staden - Migration och stadsförändring i Stockholm efter., Värnamo: Stockholmia Förlag.

MacKinnon, D. P., Lockwood, C. M. \& Williams, J. 2004. 'Confidence Limits for the Indirect Effect: Distribution of the Product and Resampling Methods', Multivariate Behavioral Research, 39, 99-128.

Newton, K. 2007. 'Social and Political Trust', in Dalton, R. J. \& Klingemann, H. D., eds., The Oxford Handbook of Political Behavior. Oxford: Oxford University Press.

Newton, K. 2001. 'Trust, Social Capital, Civil Society, and Democracy', International Political Science Review, 22, 201-214.

Nyqvist, F., Nygård, M. \& Jakobsson, G. 2012. 'Social Participation, Interpersonal Trust, and Health: A Study of 65- and 75-year-olds in Western Finland', Scandinavian Journal of Public Health, 40, 431-438. 
Örebro Municipality. 2012. The Municipal Statistical Database, http://www.orebro.se/3843.html.

Örebro Police. 2009. En liten bok om Vivalla - Problem- och resursinventering 2009, Örebro: Örebro Police, Criminal Intelligence Service.

Ostrom, E. 1990. Governing the Commons: The Evolution of Institutions for Collective Action. Cambridge University Press.

Paternoster, R., Brame, R., Piquero, A. \& Mazerolle, P. 1998. 'Using the Correct Statistical Test for the Equality of Regression Coefficients', Criminology. 14, 859-866.

Patterson, O. 1999. 'Liberty Against the Democratic State: On the Historical and Contemporary Sources of American Distrust', in Warren M. E., ed., Democracy and Trust. Cambridge: Cambridge University Press.

Persson, M. 2013. 'The Relative Importance of Institutional Trust in Countering Feelings of Unsafety in Disadvantaged Neighbourhoods', European Spatial Research and Policy, 20, 7395.

Preacher, K. J. \& Hayes, A. F. 2008. 'Asymptotic and Resampling Strategies for Assessing and Comparing Indirect Effects in Multiple Mediator Models’, Behavior Research Methods, 40, 879-891.

Putnam, R. D. 2000. Bowling Alone: The Collapse and Revival of American Community. New York: Simon and Schuster.

Putnam, R. D. 2007. 'E Pluribus Unum: Diversity and Community in the Twenty-first Century: The 2006 Johan Skytte Prize Lecture', Scandinavian Political Studies, 30, 137-174.

Robbins, B. G. 2012. 'Institutional Quality and Generalized Trust: A Nonrecursive Causal Model', Social Indicators Research, 107, 235-258.

Ross, C. E., Mirowsky, J. \& Pribesh, S. 2001. 'Powerlessness and the Amplification of Threat: Neighborhood Disadvantage, Disorder, and Mistrust', American Sociological Review, 66, 568591.

Rousseau, D. M., Sitkin, S. B., Burt, R. S. \& Camerer, C. 1998. 'Not so Different After All: A Cross-Discipline View of Trust’, Academy of Management Review, 23, 393-404.

Rothstein, B. 2001. 'Social Capital in the Social Democratic Welfare State', Politics and Society, 29, 207-241. 
Rothstein, B. \& Stolle, D. 2008. 'The State and Social Capital: An Institutional Theory of Generalized Trust', Comparative Politics, 40, 441-459.

Selig, J. P. \& Preacher, K. J. 2008. 'Monte Carlo Method for Assessing Mediation: An Interactive Tool for Creating Confidence Intervals for Indirect Effects’ [Computer software].

Sharma, S., Durand, R. M. \& Gur-Arie, O. 1981. 'Identification and Analysis of Moderator Variables', Journal of Marketing Research, 18, 291-300.

Stolle, D., Petermann, S., Schmid, K., Schönwälder, K., Hewstone, M., Vertovec, S. \& Heywood, J. 2013. 'Immigration-Related Diversity and Trust in German Cities: The Role of Intergroup Contact', Journal of Elections, Public Opinion and Parties, 23, 279-298.

Stolle, D., Soroka, S. \& Johnston, R. 2008. 'When Does Diversity Erode Trust? Neighborhood Diversity, Interpersonal Trust and the Mediating Effect of Social Interactions’, Political Studies, 56, 57-75.

Sønderskov, K. M. \& Dinesen, P. T. 2015. 'Trusting the State, Trusting Each Other? The Effect of Institutional Trust on Social Trust’, Political Behavior, 38, 179-202.

Uslaner, E. M. 2000. 'Producing and Consuming Trust', Political Science Quarterly, 115, 569590.

Uslaner, E. M. 2006. ‘Does Diversity Drive Down Trust?’ FEEM Working Paper No. 69.2006. Available at SSRN: http://ssrn.com/abstract=903051 or http://dx.doi.org/10.2139/ssrn.903051

Uslaner, E. M. 2013. ‘Trust as an Alternative to Risk’, Public Choice, 157, 629-639.

Van Craen, M. 2013. 'Explaining Majority and Minority Trust in the Police’, Justice Quarterly, 30, 1042-1067.

van der Meer, T. \& Tolsma, J. 2014. 'Ethnic Diversity and Its Supposed Detrimental Effects on Social Cohesion', Annual Review of Sociology, 40, 459-478.

de Vroome, T., Hooghe, M. \& Marien, S. 2013. 'The Origins of Generalized and Political Trust Among Immigrant Minorities and the Majority Population in the Netherlands', European Sociological Review, 29, 1336-1350.

Walklate, S. 1998. 'Crime and Community: Fear or Trust?’ British Journal of Sociology, 49, $550-569$.

You, J. S. 2012. Social Trust: Fairness Matters More than Homogeneity. Political Psychology, 33, 701-721. 
Zhao, X., Lynch, Jr., J. G. \& Chen, Q. 2010. 'Reconsidering Baron and Kenny: Myths and Truths about Mediation Analysis', Journal of Consumer Research, 37, 197-206. 
Appendix 1: Table A1. Structural model results with raw regression weights and standard errors

\begin{tabular}{|c|c|c|c|c|}
\hline \multirow[t]{2}{*}{ Multi-group by area } & \multicolumn{2}{|c|}{ Model 2a: Örebro $(\mathrm{N}=236)$} & \multicolumn{2}{|c|}{ Model 2b: Vivalla $(\mathbf{N}=167)$} \\
\hline & $\begin{array}{l}\text { To: Crime- } \\
\text { related insecurity }\end{array}$ & $\begin{array}{l}\text { To: } \\
\text { Generalized } \\
\text { trust }\end{array}$ & $\begin{array}{l}\text { To: Crime- } \\
\text { related insecurity }\end{array}$ & $\begin{array}{l}\text { To: Generalized } \\
\text { trust }\end{array}$ \\
\hline \multicolumn{5}{|l|}{ From: } \\
\hline Trust in government & $-0.046(0.068)$ & $0.226(0.087)$ & $-0.393(0.105)$ & $0.007(0.140)$ \\
\hline $\begin{array}{l}\text { Trust in legal } \\
\text { institutions }\end{array}$ & $-0.118(0.068)$ & $0.063(0.086)$ & $0.098(0.092)$ & $0.156(0.117)$ \\
\hline $\begin{array}{l}\text { Crime-related } \\
\text { insecurity }\end{array}$ & - & $-0.629(0.122)$ & . & $-0.357(0.152)$ \\
\hline \multicolumn{5}{|l|}{ Controls } \\
\hline Education level & $-0.295(0.068)$ & $-0.134(0.087)$ & $-0.162(0.082)$ & $0.140(0.104)$ \\
\hline Age & $0.003(0.003)$ & $0.007(0.003)$ & $0.003(0.004)$ & $0.006(0.005)$ \\
\hline Non-European & $0.166(0.159)$ & $-0.562(0.203)$ & $0.332(0.149)$ & $-0.458(0.190$ \\
\hline Unemployed & $-0.236(0.337)$ & $-0.240(0.431)$ & $-0.199(0.233)$ & $-0.295(0.293)$ \\
\hline Social capital & $0.006(0.034)$ & $0.066(0.044)$ & $0.025(0.053)$ & $0.074(0.066)$ \\
\hline
\end{tabular}




\section{Notes}

\footnotetext{
${ }^{1}$ Generalized trust is defined as the belief that others in general act in favour of our interests if they know of them, and do not act maliciously.

${ }^{2}$ The design of this study does not capture the particularities of this form of crime. This is arguably a limitation of the study, because many researchers have shown that the home is the most dangerous location for women in terms of victimization.

${ }^{3}$ After subtracting those responses that were sent back blank.

${ }^{4}$ As a consequence of the difficulty in obtaining high response rates (which is typical in contemporary segregated areas), research has been conducted on the statistical effects and limitations that a limited sample implies. These studies show very limited differences due to non-responses (Langer 2003). Langer also emphasizes that non-responses have received disproportionate attention as far as reliability in relation to other methodological questions, such as constructs and choice of statistical method, is concerned.

${ }^{5}$ It should also be noted that while the questions do not have strictly equal formulations, they do include comparable alternatives.

${ }^{6}$ Apart from chi-square, which is expected to be significant for small samples with complex models, we use the comparative fit index and the root mean square error of approximation (RMSEA), with a test, $p$ close, that tests whether the population RMSEA is not above 0.05, these being common examples of incremental and absolute fit indices (Hair et al. 2010). In conclusion, it has been suggested that this information is enough to properly judge model fit (Hair et al. 2010).

${ }^{7}$ Both the CFA made here and the one made in Table 2 show good fit to data. Furthermore, despite having few indicators (items) the Cronbach's alpha for the two latent variables are satisfactory ( $>0.7$ ) (Nunally 1978).

${ }^{8}$ We used a one-sided test, which is appropriate for directional hypotheses. This effect would not have been statistically significant at the $5 \%$ level if we had used a two-sided test.

${ }^{9}$ This makes sense from the perspective that trust in political institutions is theoretically more likely to spill over into trust in legal institutions than the other way around, since the politicians shape the legal system.
} 